\title{
Provincial Training of Medium Occupation School Professional Backbone Teacher 6 Years Training Experience
}

\author{
Qiang Wang \\ College of Electrical and Information Engineering, Lanzhou University of Technology, Lanzhou 730050, \\ China \\ wangqiang@lut.cn
}

\begin{abstract}
Expounds the six years of working experience in secondary vocational school professional provincial backbone teachers training, professional backbone of secondary vocational school teacher training organization process to do a comprehensive review, the purpose of training is to make the training teachers to become has the exemplary role of the secondary vocational schools "double division type" professional backbone. Through six years of training work, for our province secondary vocational school has trained a large number of much-needed professional backbone teachers, contributed a lot to the improvement of vocational education in our province, has obtained the good effect.
\end{abstract}

KEYWORD: Secondary vocational school; Professional backbone teachers; Training work; Vocational education

\section{INTRODUCTION}

For secondary vocational school, through training to improve the whole quality of the secondary vocational school teachers, especially the teaching innovation and practice ability, perfect the training system to cultivate teachers, optimize the structure of teachers' team, promote vocational education teachers team construction work, To speed up the training of professional backbone teachers a modern educational quality and innovation spirit, to provide a powerful guarantee for the sustainable, rapid, healthy development of occupation education[1,2].

In order to make the secondary vocational schools better professional backbone teachers training, make training teacher "teacher + engineer" type of "double division type" professional backbone. Each session of training in accordance with the process of the practice of various professional training, to summarize the training experience, and according to the actual needs of students, aims to: Raise the level of teachers' professional theory and professional technology, with strong professional skills[3]; Improve teachers' teaching methods and curriculum development ability, and can according to the law of new teaching in vocational education, the teaching idea, the courses of analysis and design of the system; Improve the level of teacher's vocational education theory, to renew the idea of vocational education, to promote teaching reform; Improve teacher education creation ability, life-long learning ability and comprehensive quality, make teachers have demonstration effect of secondary vocational school of "double division type" professional backbone.

\section{TRAINING REQUIREMENTS}

Through training, training of teachers must meet the following basic requirements: Love of secondary vocational education career, conscientiously implement the party's education policy, With the spirit of innovation and reform of consciousness, Do both imparting knowledge and education to cultivate people, can be used as a model and example, serious working attitude and caring students; To use scientific methods to evaluate the test and analysis of various types of teaching good, is good at teaching practice sublimation as theory, summarizes some practical teaching methods, and gives its implementation; Is adapt to the requirements of the quality education of new education ideas and education concept, with high cultural accomplishment, rich and solid professional knowledge and theory, Good at constantly absorbing domestic and foreign professional technology of the latest scientific and technological achievements, constantly improve the level of secondary vocational school teachers' education teaching, improve teachers' ability of application level and the analysis and design, strengthen practical teaching ability, To improve teachers' professional knowledge structure, adapt to the needs of modern teaching[4,5,6]; Make 
full use of all kinds of modern education technology in teaching, can adapt to modern network education and computer aided teaching.

\section{THE TRAINING OBJECT}

Secondary vocational school course or practice guidance teachers and satisfy the following conditions: Teachers' position at or above the intermediate level and has a strong teaching and scientific research ability, love the professional education career, work a strong sense of responsibility; Engaged in this professional (or similar) teaching work for 5 years and age are generally not more than 45 years of age[6,7].

\section{TRAINING METHODS}

All training adopts "base + enterprise practice" offjob training mode[8,9]. Training contents include the following aspects: teaching theory and methods, professional knowledge and skills training. The main training content is the specialized theory and skills of teaching research and practice. Take students as the main body, teacher as the leading factor, the theoretical study, experimental training and the combination of expert lectures training form, the combination of centralized lectures and panel discussion teaching method, make the teacher timely tracking field, on the basis of new knowledge, new technology, grasp new technology and new method in the area[10].

\section{TRAINING ARRANGEMENT}

Training according to the instruction from the provincial education department, combined with the specific situation of the secondary vocational school skills contest, in accordance with the training project, The choice of training programs from electrical and electronic vocational skills contest game subject in recent years as a training plan. Including mechanical and electrical integration, machine tool electric control, programmable controller application technology, single-chip computer application technology, electronic products assembly and debugging. Each specific training project is adjusted according to the trainee survey feedback and market demand, through the Provincial Department of education, occupation education and adult education department for approval and implementation.

Lanzhou University of Technology of College of Electrical and Information Engineering has a long history, teachers have abundant teaching experience, teaching management measures to perfect, advanced experimental equipment and experimental conditions. In order to make the training to achieve good results, ensure the quality of training, we arranged the good teaching effect, and serious and responsible, have rich practical experience of teachers.

For secondary vocational school teachers, in addition to vocational skills training, also need to improve their own quality, strengthen ethics construction, improve the humanities accomplishment [5-9]. In this regard, we also invited the leadership of the Department of education and the relevant experts to make a report to training students, help students to improve the level and increase awareness of the occupation education. Training classes after the ceremony, to give each student a student handbook, which includes the training management system, training plan, training schedule, training courses etc..

During the whole training, the training director and teacher in charge's mobile phone must remain open 24 hours, mainly in order to ensure the safety of your training, deal with emergency, try to meet the requirements of students. In short, sincerity, patience, compassion is to training students. I think the trainees should feel.

\section{INSPECTION WAY}

\subsection{Assessment content}

Complete a teaching plan and teaching demonstration; Writing a teaching and research papers or training summary report, and complete the training work; Cooperation enterprise for training students practice and professional skill levels to make evaluation.

\subsection{Assessment criteria}

Learned to use the teaching theory and method to write a teaching plan and teaching demonstration of not less than two hours, Required to focus on prominent, moderate difficulty, The logic is clear and smooth expression, conform to the specifications; Teaching research papers or training summary report not less than 3000 words, substantial in content, there are more original ideas, has a certain guiding significance to the teaching theory; Seriously to participate in the enterprise practice, through professional skills appraisal.

\section{TRAINING MANAGEMENT AND MEASURES}

\subsection{Teaching management}

The electronic information engineering department is responsible for the supervision and check the implementation of training plan. In order to ensure 
the experiment, training, design, production of all practical training link normal development, in addition to every teacher should participate in teaching practice guidance, during the training, each experimental or laboratory is equipped with a professional teachers. Training during each student if you have any good Suggestions and specific requirements, please timely feedback to the head of the training and training teachers, we will try to meet the requirements of training, make training effect is satisfactory.

\subsection{Company internship}

Let the students learn and familiar with related enterprises advanced technology, production process, management system and culture, post standard, talent demand situation. After the internship students, writing practice report.

\subsection{Visit the company}

Through a tour of the enterprise, a is to make the students familiar with this professional in the industry present situation and the development situation, the second is to know the knowledge structure and the technical requirements of the industry, in order to make clear the purpose of training.

\section{TRAINING EFFECT}

Since 2008, the training base of electronic and Information Engineering Department of Telecommunication College of Lanzhou University of Technology undertakes the medium occupation school of Gansu province professional backbone teachers training a total of six times, a total of training from the province of the medium occupation school professional backbone teachers about 400 or so. Undertake the training of teachers is Lanzhou University of Technology state-level teaching team of backbone teachers, They are rich teaching experience and practice ability is strong, serious and responsible teacher. Six years of training have achieved good effect, and the training of students' praise and provincial education department related departments fully affirmed.

College of Electrical and Information Engineering of Lanzhou University of Technology training base in finish the task on the basis of current training program, according to the requirement of the vocational education and adult education province department of education, to carry out the teachers' professional skill tournament competition activities. A fair and just competition, warm and orderly, the teacher full enthusiasm to participate in vocational skills competition. After the competition, through theoretical analysis of the evaluation, evaluation of the production process, the scene debugging assessment, and publicity, to participate in the teacher's winners won a prize of vocational skills contest.

Every time after the training to report for duty, training start ceremony, held by the provincial education department in vocational education and adult leadership do pep talk, clear training task, training requirements and training purpose. Training after graduation ceremony, held by the provincial education department of vocational education and adult education leadership and telecommunications college leadership award certificate.

\section{CONCLUSION}

College of Electrical and Information Engineering of Lanzhou University of Technology in recent years, have undertaken relevant enterprise training task, bear the provincial education department training task, feel a great responsibility. We adhering to the consistent tradition and style, to do will be steadfast, to do earnestly, be responsible for training students, obtain good effect. Our training, training student's widespread high praise. Of course, in the process of training, we also harvested a lot, some students still keep in touch with us, every holiday, greetings sent text messages. There are some students in the process of training of tenacity, determination to overcome difficulties, as well as interest in learning and improve their ability to have moved us. Teaching and learning is a process of improving each other.

\section{REFERENCES}

[1] Wang Jing, Zhu Mei-jing, Our country secondary vocational school teacher training research review and trend. Continue to education research. 2011,(07):85-87

[2] Chen Xiao, Wei Na. Different types of secondary vocational education teacher training base of the evaluation and comparison. Secondary vocational education. 2012,(24):35-39

[3] Ning Yong-hong, Ling Zhi-jie. Weak Links in Teaching Staff Construction of Secondary Vocational Schools and the Countermeasures. Vocational and technical education. 2012,33(13):49-54

[4] State Board of Education. Nationwide backbone Vocational Technical School (center) Symposium on construction work. http://baike.baidu.com/view/3736450. htm.

[5] The CPC Central Committee and State Council. On deepening education reform and advancing quality education decision.

http://www.people.com.cn/item/flfgk/gwy/jkww/j990613. html. 
[6] The Ministry of education and other seven ministries. Some opinions on Further Strengthening the work of the occupation education.

http://baike.baidu.com/view/2994075.htm

[7] Decisions of the State Council on vigorously develop vocational education. http://www.fzrxly. com/zjlt/5.htm.

[8] State Board of Education. Principles opinion 21st century deepen the reform of vocational education. http://www.people.com.cn/item/flfgk/gwyfg/1998/206003 199801.html.

[9] Xinhua news agency. The national medium and long-term education reform and development plan outline (20102020). http://www.gov.cn/jrzg/2010-07/29/content_1667143.htm.

[10] Shao Peng-fei. Secondary vocational school teachers' training in my opinion. Vocational education BBS. 2010,(19):69-71 